\title{
Breast cancer tumor markers
}

\author{
Robby Kumar ${ }^{1}$, Amar Nagesh Kumar ${ }^{1}$, Anuj Srivastava ${ }^{2}$ \\ 1. Department of Biochemistry, SSR Medical College, Mauritius. 2. Department of Surgery, SSR Medical College, Mauritius \\ Correspondence: Robby Kumar, Department Of biochemistry, SSR Medical College, Mauritius. \\ Email: kumarrobby@gmail.com
}

Received: September 22, 2011 Accepted: December 28, 2011 Published: February 1, 2012

DOI : $10.5430 /$ jst.v2n1p43

URL: http://dx.doi.org/10.5430/jst.v2n1p43

\section{Abstract}

Breast cancer is one of the most common cancer in women, presented with a lump and skin colour change, is one of the commonest cancer in women. A wide variety of tumor markers viz. uPA, BRCA1 \& 2, Ki76, ER, PR, HER etc. are used for establishing carcinoma of breast but none being a proper diagnostic tool for early detection, though each one has its own prognostic value. Though proposed but only few are used in clinical practice, research studies are still ongoing to identify and establish new biochemical parameters/markers that can be of used not only in advanced disease, but also in early stages of the diagnostic workup of breast cancer.

\section{Key words}

Biomarkers, Carcinoma, Tumor

\section{Introduction}

Tumor biomarkers are substances which show up or are elevated in blood, urine or tumor. These substances can be hormone, proteins, peptides etc. Tumor markers can be specific or non-specific, making it useful in detection, diagnosis and prognosis of cancer. Breast cancer, a heterogeneous disease, is one of the most common cancers in women, after skin cancer, representing about $16 \%$ of total female cancers. Breast cancer is less evident in women under 40 years. Breast cancer also known as malignant breast neoplasm is tumor originating from the inner lining of milk ducts or the lobules that supply the ducts with milk. Depending on which it is known as ductal carcinomas and lobular carcinoma respectively. Breast cancer is generally presented with lump in breast, nipple change or discharge and skin contour changes. Though a wide range of tumor markers have been identified for breast cancer but lack of sensitivity and specificity for early diagnosis is main disadvantage. Consequently, the available markers are of no value in either screening or diagnosing early breast cancer. Sometimes, these tumor markers are helpful but have to be used together with other tests such as biopsy, mammograms, and ultrasound and breast MRI's. These tests are powerful, highly sensitive and specific to detect breast cancer in early stages even before symptoms are manifested ${ }^{[1]}$. It is specifically to be noted that tumor marker tests alone cannot provide enough or rather no information to screen/diagnose breast cancer. The main aim of this review is to have a brief insight of all the existing conventional and emerging biomarkers, and presenting the most effective biomarkers for breast cancer, as treatment of breast cancer is possible only if it is detected in early stages.

\section{Markers}

There is wide range of tumor markers but none being effective. 
Conventional tumor markers: These include: uPA, PAI-1, CA 15-3, CA 27.29, CEA, ER, PR, HER2, BRCA1, BRCA2 and Ki67.

Emerging tumor markers: Includes: p53 protein, blc-2, ARF, TBX2/3, Cyclin D, Clyclin E, VEGF, hTERT DNA, Glycan biomarkers, Stem cell markers, topoisomerase IIa, Serum autoantibodies, PPIA, PPRDX2, FKBP52 and Micro RNA's.

\section{Urokinase plasminogen activator (upa); plasminogen activator inhibitor (pai-1)}

uPA, produced as proprotein i.e. pro uPA, which is cleaved to form a $53 \mathrm{Kda}$ serine protease. Major function of this protease is to cleave plasminogen to form active protease plasmin and is involved in tissue remodelling, inflammation, fertilization, and embryogenesis and tumor invasion. PAI-1 is a glycoprotein, a serine protease inhibitor- binds to tPA and uPA, prevents cleavage of plasminogen ${ }^{[2]}$. PAI-1 has a role in cancer migration, invasion, inflammation, neutrophil recruitment, proliferation of smooth muscle cells and obesity ${ }^{[3]}$. uPAR is a cell surface receptor for uPA and is required for endocytosis of uPA-PAI-1 complexes and UPA activation. In breast cancer over expression of uPAR, PAI-1 and uPA attributes to decreased survival. UPA and PAI-1 has poor prognostic indicators for member of cancers, as they have been shown to be elevated in cancers other than that of breast ${ }^{[4]}$.

\section{CA 15-3; CA 27.29 and CEA}

Increased CA 15-3 in serum is reported in about $10 \%$ of patients in early breast cancer and is subsequently elevated as the disease progresses. An increase of CA 15-3 five to ten times above normal upper limit can predicts breast cancer; however a low value cannot exclude metastasis ${ }^{[5,6]}$, making this more of prognostic marker rather than diagnostic marker.

\section{Ki67}

ki67 antigen is used to evaluate the proliferative activity of breast cancer, though its role in prognosis is still unclear it can be used as a marker for this. ${ }^{7}$ ki67 reacts with nuclear non histone protein in all active phases of cell cycle. The presence of ki67 in all proliferating cells makes it a weak marker for diagnosis ${ }^{[7,8]}$.

\section{ER, PR, HER}

ER is probably the most powerful diagnostic and prognostic marker for breast cancer. About $60 \%$ of women below 50 years has been reported with ER positive and is increased up to $80 \%$ in women's above 50 years. Oestrogen hormone is an established risk factor for breast cancer, which exerts its effect via oestrogen receptors (ER) - a nuclear protein. Two types of ER is seen ERa and ERb; ERa is expressed in upto $70 \%$ of all breast cancer. ER is an important mediator of carcinogenesis, inhibition of this can lead to the breast cancer therapy ${ }^{[9,10]}$. PR is controlled by oestrogen therefore it shows the indication of proper functioning of ER pathway and thus PR assay can be used for prognostic purposes. ${ }^{11}$ HER2Human epidermal growth factor 2 oncogene encodes epidermal growth factor receptor (EGFR). HER2 is important in cell differentiation, adhesion and motility. In nearly $20 \%$ of breast cancer, overexpression of this gene leads to abnormal high level of glycoprotein. HER2 positivity is associated with number of tumors and cell growth owing to its low diagnostic and prognostic value ${ }^{[11]}$.

p53 tumor suppressor gene products are one the major mechanism to control cancer. Inactivation of this gene leads to overexpression of p53 protein. Though overexpression is seen highly in breast cancer but is also associated with other tumors making it a poor diagnostic and prognostic marker ${ }^{[12]}$.

\section{bcl2}

Cancer cell does not undergo apoptosis. Bcl2 protein regulates the apoptosis in normal cellular pathway i.e. antiapoptotic pathway. Increase in bcl2 leads to cell survival. Bcl2 overexpression is reported in many tumors and lymphomas. In breast cancer it is increased due to oestrogen, and is less evident in other tumors ${ }^{[13]}$. 


\section{ARF}

p14 ARF protein blocks cell cycle at G1 and G2 . It acts with correlation with p53, and inhibits growth of cancerous cells by activating $\mathrm{p} 53^{[9]}$.

\section{TBX2/ 3}

TBOX protein 2 and 3 affects dimerization and DNA binding, both generally affect tumor development through down regulation of ARF $\mathrm{p} 53$. TBX2/3 has been overexpressed in breast cancer ${ }^{[9]}$.

\section{Cyclin D1 and Cyclin E}

Cyclin D1 is associated with G1 phase of cell cycle and is synthesised in response to growth factors. Cyclin D1 is overexpressed in many tumors and is detected in half of the breast cancer.

Cyclin $\mathrm{E}$ is the limiting factor for G1 phase progression and S phase entry. Overexpression is seen in about $40 \%$ of breast cancer ${ }^{[9]}$.

\section{BRCA1 and BRCA2}

Mutation in genetic level of BRCA1 and BRCA2 genes are strong evidence of breast cancer with nearly $40-80 \%$ chance of developing cancer. Genetic testing of BRCA mutation is one of the powerful tools for predicting Breast cancer ${ }^{[14]}$.

\section{VEGF}

VEGF is associated with angiogenesis in breast cancer and is required for tumor growth and metastasis. VEGF is reported to be overexpressed in breast cancer ${ }^{[9]}$.

\section{hTERT DNA}

Human telomerase reverse transcriptase (hTERT) underlies cancer cell immortalization, and the expression of hTERT is regulated strictly at the gene transcription ${ }^{[13]}$. Circulating human telomerase reverse transcriptase hTRET DNA is one of the better markers for diagnosis of breast cancer ${ }^{[15]}$.

\section{Glycan biomarkers}

It's still under research; certain links with cancer and altered protein glycosylation have been reported. Once established this can be a highly sensitive method for detecting early breast cancer ${ }^{[16]}$.

\section{CD44 and CD24}

Stem cell CD44 and CD24 evaluation in colon, breast and prostate cancer can be a candidate for breast cancer diagnosis and prognosis ${ }^{[17,18]}$.

\section{Micro RNA}

Recently the miRNA has been shown to be deregulated in human breast cancer leading to genomic changes. Evaluation of this can be a better candidate for breast cancer marker ${ }^{[10]}$.

\section{Conclusion}

Though a clear biomarker for carcinoma of breast has not yet found but assessing certain parameters like uPA, BRCA1 \&2, Ki76 and ER, PR, HER can give an indication of breast cancer, though a negative value or normal values doesn't rule out the possibilities for the breast cancer, so as for detecting early breast cancer, some unconventional markers needed to be assayed such as micro RNAs. hTERT gene, and glycan biomarkers. These though still under research can give a proper 
indication of breast cancer. However research is still needed to establish a proper protocol for detection of early breast cancer.

\section{References}

[1] J. Michael Dixon, Breast cancer: diagnosis and management, Elsevier Health Sciences, 2000

[2] D. Palmieri, J. W. Lee, R. L. Juliano, and F. C. Church, "Plasminogen activator inhibitor-1 and -3 increase cell adhesion and motility of MDA-MB-435 breast cancer cells," Journal of Biological Chemistry, vol. 277, no. 43, pp.40950-57,2002.

PMid: 12176977 http://dx.doi.org/10.1074/jbc.M202333200

[3] Jennifer C. Carter1 and Frank C. Church, Obesity and Breast Cancer: The Roles of Peroxisome Proliferator-Activated Receptor- $\gamma$ and Plasminogen Activator Inhibitor-1, PPAR Research Volume 2009

[4] L. Strandberg, D. Lawrence, and T. Ny, "The organization of the human-plasminogen-activator-inhibitor-1 gene. Implications on the evolution of the serine-protease inhibitor family," European Journal of Biochemistry, vol. 176, no. 3, pp.609-16,1988. PMid: 3262512 http://dx.doi.org/10.1111/j.1432-1033.1988.tb14320.x

[5] Michael J. Duffy, Serum Tumor Markers in Breast Cancer: Are They of Clinical Value? Clinical Chemistry 52:3 345-51(2006)

[6] Anonymous. Clinical practice guidelines for the use of tumor markers in breast and colorectal cancer. Adopted on May 17,1996 by the American Society of Clinical Oncology. J Clin Oncol 1996; 14:2843-77. PMid: 8874347

[7] E de Azambuja1,2, F Cardoso1, G de Castro Jr1, M Colozza3, MS Mano1, V Durbecq1, C Sotiriou1, D Larsimont1,MJ Piccart-Gebhart1 and M Paesmans, Ki-67 as prognostic marker in early breast cancer: a meta-analysis of published studies involving 12155 patients,British Journal of Cancer (2007)96,1504-13 PMid: 17453008

[8] Cattoretti G, Becker MH, Key G, Duchrow M, Schluter C, Galle J, Gerdes (1992) Monoclonal antibodies against recombinant parts of the Ki-67 antigen (MIB 1 and MIB 3) detect proliferating cells in microwave- processed formalin-fixed paraffin sections. J Pathol 168:357-63 PMid: 1484317 http://dx.doi.org/10.1002/path.1711680404

[9] Pankaj Taneja, Dejan Maglic,Fum itake Kai, Sinan Zhu, Robert D. Kendig,Elizabeth A. Fry, and Kazushi Inoue Classical and Novel Prognostic Markers for Breast Cancer and their Clinical Significance, Clin Med Insights Oncol. 2010;4:15-34. Published online 2010 April 20. PMid: 20567632

[10] Cherie Blenkiron. Leonard D Goldstein et, al. MicroRNA expression profiling of human breast cancer identifies new markers of tumor subtype, Genome Biology 2007,8:R214. PMid: 17922911 http://dx.doi.org/10.1186/gb-2007-8-10-r214

[11] S J L Payne, R L Bowen, J L Jones \& C A Wells1, Predictive markers in breast cancer - the present, Histopathology 2008, 52, 82-90. PMid: 18171419 http://dx.doi.org/10.1111/j.1365-2559.2007.02897.x

[12] Beck T, Weller EE, Weikel W, Brumm C, Wilkens C, Knapstein PG. Usefulness of immunohistochemical staining for p53 in the prognosis of breast carcinomas: correlations with established prognosis parameters and with the proliferation marker, MIB-1.Gynecol Oncol. 1995 Apr;57(1):96-104. PMid:7705708 http://dx.doi.org/10.1006/gyno.1995.1104

[13] Grace M. Callagy,1,4 Paul D. Pharoah, Bcl-2 Is a Prognostic Marker in Breast Cancer Independently of the Nottingham Prognostic Index, Clin Cancer Res 2006;12(8) April 15,2006

[14] Olufunmilayo I. Olopade,1 Tatyana A. Grushko,1 Rita Nanda,1 and Dezheng Huo2, Advances in Breast Cancer: Pathways to Personalized Medicine, Clin Cancer Res 2008;14(24) December 15,2008

[15] ROSA DIVELLA, Circulating hTERT DNA in Early Breast Cancer, Anticancer Research July 1, 2009 vol. 29 no.7:2845-2849 , PMid: 19596972

[16] Zuzana Kyselova,1 Yehia Mechref, Breast Cancer Diagnosis and Prognosis through Quantitative Measurements of Serum Glycan Profiles, Clinical Chemistry 54:7 1166-75(2008)

[17] Al-Hajj M, Wicha SM, Benito-Hernandez A, Morrison SJ, Clarke MF: Prospective identification of tumorigenic breast cancer cells. Proc Natl Acad Sci USA 2003, 100:3983-88. PMid:12629218 http://dx.doi.org/10.1073/pnas.0530291100

[18] Christine Fillmore1 and Charlotte Kuperwasser, Human breast cancer stem cell markers CD44 and CD24: Enriching for cells with functional properties in mice or in man? Breast Cancer Research 2007,9:303 PMid:17540049 http://dx.doi.org/10.1186/bcr1673

[19] Dakang Xu, Julie Dwyer , He Li, Wei Duan, Jun-Ping Liu; Ets2 Maintains hTERT Gene Expression and Breast Cancer Cell Proliferation by Interacting with c-Myc; August 29, 2008 The Journal of Biological Chemistry, 283,23567-80 PMid: 18678878 http://dx.doi.org/10.1074/jbc.M800393200

[20] S J L Payne, R L Bowen, J L Jones, C A Wells, Predictive markers in breast cancer - the present, Histopathology, Volume 52, Issue 1, pages 82-90, January 2008. PMid: 18171419 